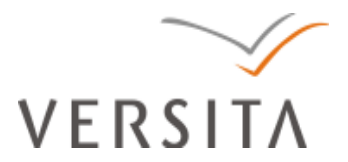

Folia Oeconomica Stetinensia

DOI: $10.2478 / \mathrm{v} 10031-010-0012-8$

\title{
ON THE NEED FOR PREVENTION IN THE PENSION SYSTEM \\ ON THE EXAMPLE OF THE DEMOGRAPHIC RESERVE FUND
}

Piotr Obidziński, Ph.D.

Department of Insurances and Capital Markets

Faculty of Economics and Management

University of Szczecin

Mickiewicza 64, 71-101 Szczecin

e-mail: piotrobi@wneiz.pl

Received 26 October 2010, Accepted 24 June 2011

\begin{abstract}
The subject of this paper is the Demographic Reserve Fund (DRF) which was established following the November 11th 1998 legal act of on the system of social security. The goal of the paper is the analysis and diagnosis of as well as the forecast for the Fund's demand for the financial means that have emerged after ageing demographic boom generation started entering the retirement age. The forecast is based on the assumptions referring to the demographic, social and economic situation of the country. These assumptions particularly refer to fertility, mortality, economic growth, earnings growth, migration, inflation, unemployment rate, structure of the population with respect to occupational groups and groups being beyond the labor force, indicators of valorization of premiums paid and services from social security, etc.
\end{abstract}

Keywords: forecast, projection, the Demographic Reserve Fund, demography, social security, retirement, baby boom.

JEL classification: C10, G23. 


\section{Introduction}

The aim of this paper is to present the evidence of demographic and socio-economic formation of the Demographic Reserve Fund (DRF) as a part of a preventive social security system in view of the projected demographic changes. The work also presents a chosen scenario (warning) of the DRF demand and conclusions on the further operation of the Fund.

\section{General characteristics of the Demographic Reserve Fund}

Demographic Reserve Fund (DRF) was established by the Law of 13 October 1998 on social insurance system. Its task is to collect long-term financial reserves at a time when the baby boomers are ageing and then eliminating the negative impact on the budget of the transition of this group of people to the age of retirement. Figure 1 shows the location of the DRF in the structure of the social security system.

A realistic objective of the Fund is to bring relief to the state budget in the most difficult periods from the demographic point of view. The first such period will be when the generation born in the postwar boom of 1946 to 1961 (period determined on the basis of a stable population model $^{1}$ ) enters retirement age. Until then, the Fund will not be started. According to the law potential sources of the DRF revenue are:

- a part of social security contributions (in 2003 they accounted for $0.1 \%$ of the base 2004 premiums increased annually by $0.05 \%$ ),

- funds from the privatization of the Treasury,

- investment income of the DRF,

- interest from deposits on the accounts are maintained by the Social Security and do not constitute income of the Social Security Fund.

With prescribed by the statute, finance expenses of the Fund are only a part of social security contributions. Income from investments of the DRF is a genuine source of revenue. In subsequent years, starting from 2009 an increasing number of people born during the postwar baby boom will enter the retirement age. At the same time the labor market will shrink in terms of the number of employees. The combination of these two factors will increase the deficit of the Pension Fund, and thus the target budget subsidy will have to be increased. Due to their volume the resulting financial implications will be a heavy burden for the state budget. Apart from the impact of the baby boomers, we have some time to deal with falling fertility and the lengthened life expectancy. Just these two determinants contribute to the growth of the Pension Fund deficit. 


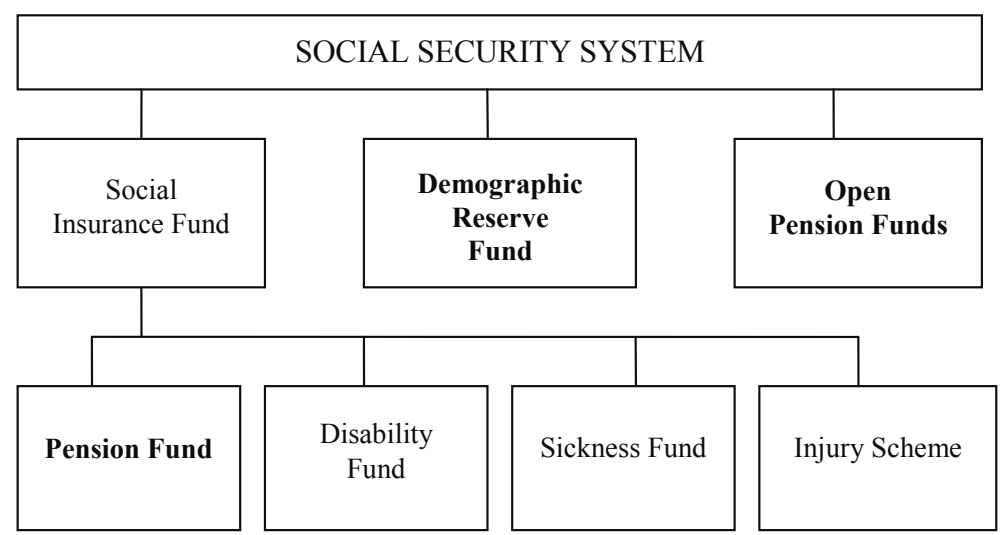

Fig. 1. The DRF in the structure of the Social Security System

Source: own calculations based on (Legal Acts, 1).

Ripple structures reinforce these negative processes. In relation to the purpose defined in the DRF establishing act ${ }^{2}$ associated with the process of wave structures, the model needs to be constructed for the Fund based on the identification of the baby boom and its financial consequences.

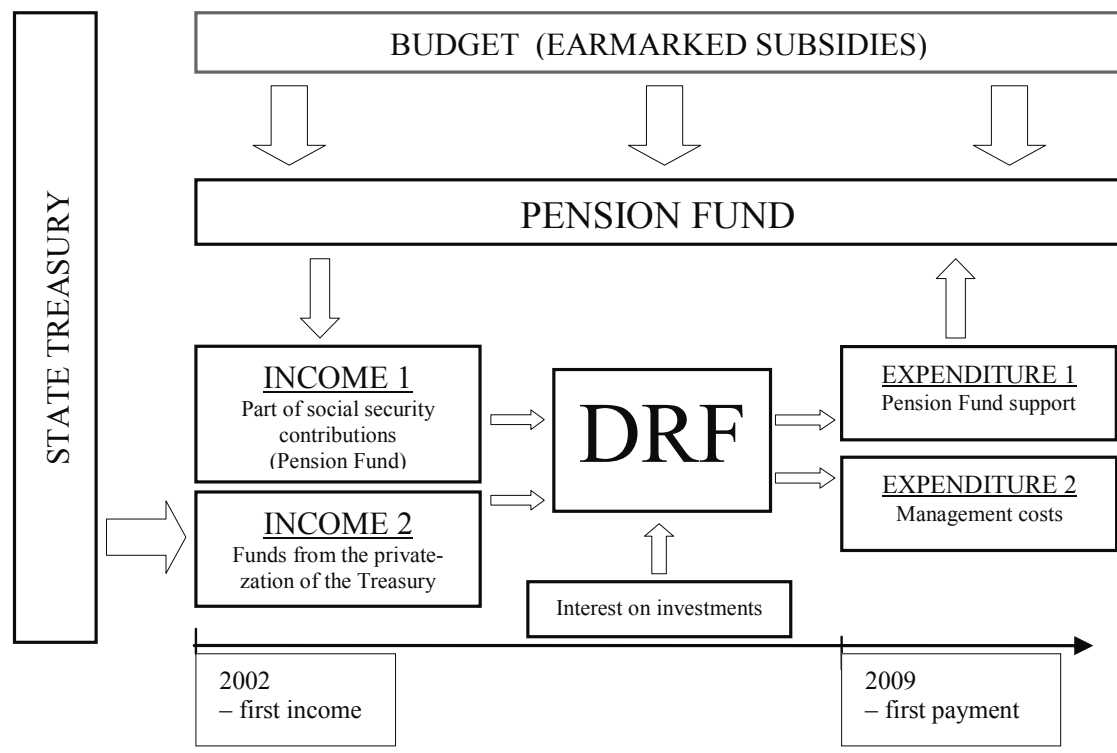

Fig. 2. Schematic operation of the DRF

Source: own calculations based on (Legal Acts, 1). 
The DRF demand in the future will have a substantial impact on the today introduced legislation (and therefore on political decisions) concerning the retirement age and the availability of and conditions for early retirement. In addition to demographics, it is the political decisions that may be the main cause for the deepening deficit of the Pension Fund in the future.

\section{Factors affecting the DRF demand}

The long-term nature of the entrusted funds of the Fund is based on an annual basis carried out by Social Security long-term forecast of moving revenue and expenditure of the Pension Fund $^{3}$. Forecasts are the basis for making assumptions about the phenomena of socio-economic and demographic impact on the demand of the Fund. The main determinants of this demand are:

- structure of the population by sex and age - the forecast based on assumptions (demographic environment):

- fertility,

- mortality,

- international migration,

- labor market - based on assumptions about the (socio-economic environment):

- structure of the population, broken down by professional groups and groups outside the workforce,

- growth,

- inflation,

- unemployment rate,

- earnings.

An additional factor influencing the size of demand is the political environment - Legal Fund. It is expressed, inter alia, in the arrangements for:

- adjustment of rates of contributions and benefits paid from social insurance,

- retirement age for men and women,

- rules for early retirement, etc.

The basis for estimates of the Demographic Reserve Fund in the coming years is the demographic projection of the size and structure of the Polish population by age based on assumptions about fertility, mortality and migration. This particular demographic situation not only affects the socio-economic situation but in reality there is also a reverse relationship, socio-economic situation determines the decisions of individuals on demographic processes. 
In particular, this relationship can be seen in the labor market, where labor supply is largely due to the demographic potential, the demand for labor is derived from the country's economic situation, and decisions about reproduction are often associated with conditions in the labor market ${ }^{4}$. Hence it is necessary to also record the characteristics of the study on the labor market (the structure of the population, broken down by professional groups and groups outside the workforce, economic growth, earnings, unemployment, inflation). In addition, DRF demand for funds is related to the legal regulations concerning the purposes and principles of the pension scheme.

\section{Demographic underlying sources of the necessary changes in the system}

The need for changes in the social insurance system is mainly driven by demographic changes. These changes are inevitable and they are mainly associated with the occurrence of so-called. wave structures (high and low- demographic pressure), which also overlaps with changing patterns of fertility and mortality. Strong waves observed structures is the result of a post-war baby boomers. Then, during the construction retirement systems after the war adopted overly optimistic assumptions about the structure of its future revenue and expenditure. Meanwhile, the number of births in the period from the end of the war until now has consistently declining trend (Figure 3), which is a result of the wave structures as well as adverse changes in the pattern of fertility.

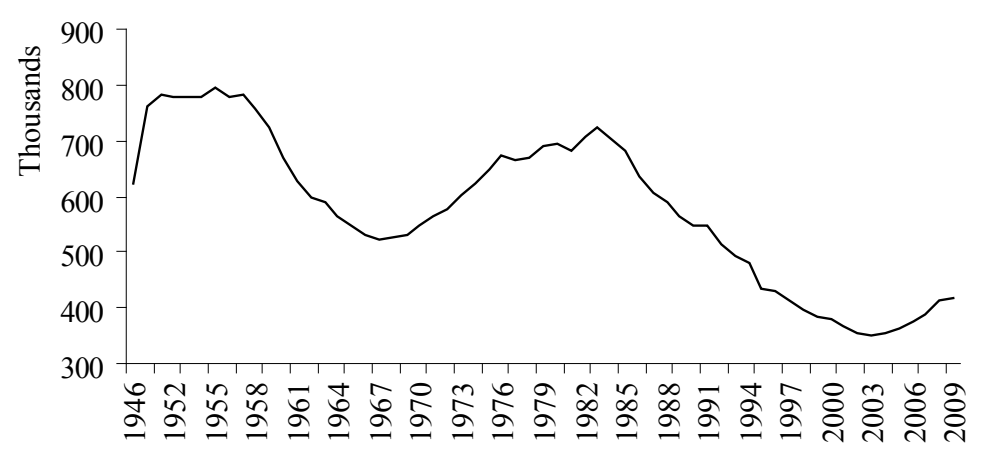

Fig. 3. Live births in the years 1946-2005

Source: own calculations based on GUS data. 
The changes are observed also in the process of mortality. By improving the quality of life of its average duration is prolonged (see Figure 5). This is largely thanks to a decrease in mortality among infants (see Figure 4).

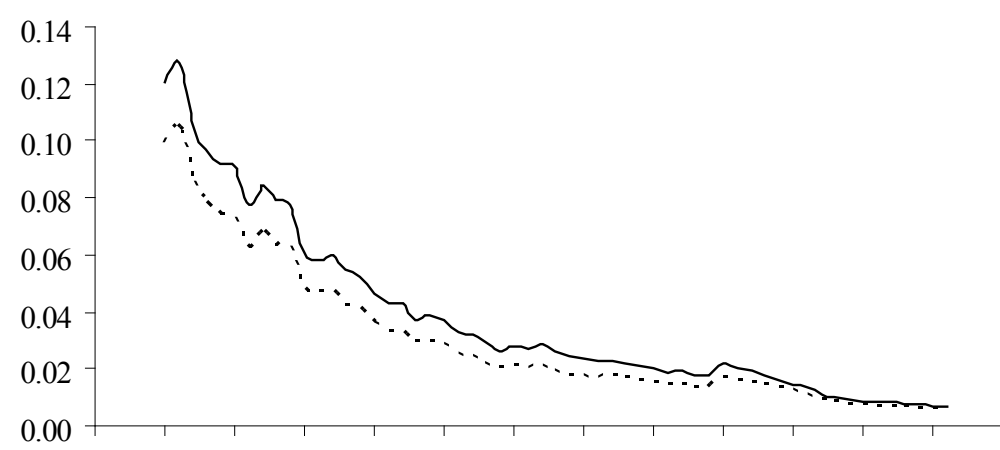

19451950195519601965197019751980198519901995200020052010

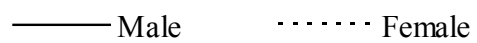

Fig. 4. The probability of death at the age of a person over the age of 0-completed year Source: own calculations based on GUS data.

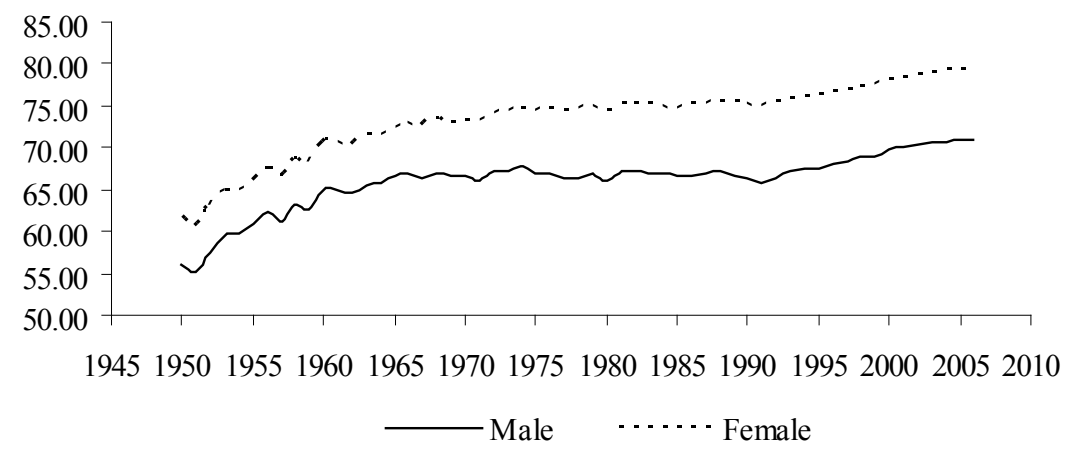

Fig. 5. The average life expectancy at age 0 -completed year

Source: own calculations based on GUS data.

\section{The selected scenario demands the Demographic Reserve Fund}

As a result, described processes and assumptions as to the further development of population projections prepared for the years 2008-2050. As a result, the assumptions used in the test period the number of births will decline and the number of deaths increased (see Figure 6). 


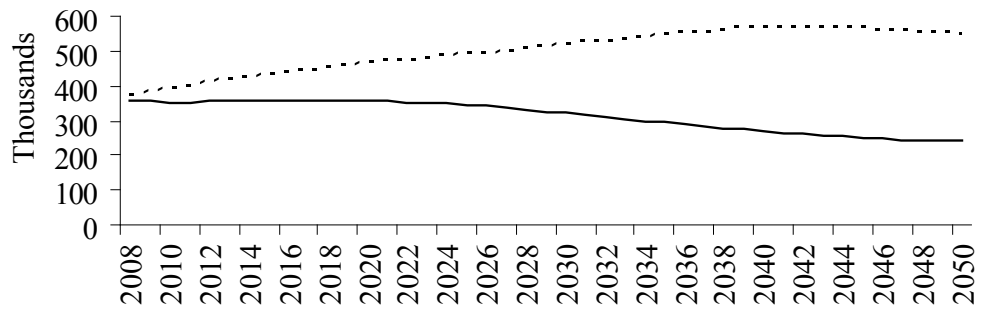

Births $\quad \cdots \cdots$ Deaths

Fig. 6. Births and deaths in the years $2008-2050$ broken down by age groups budget Source: own calculations based on GUS data.

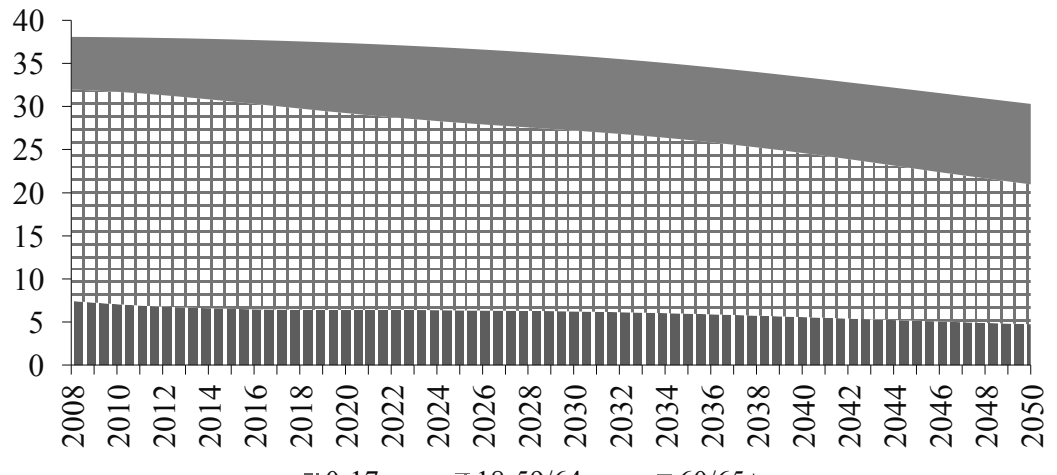

$$
\text { II } 0-17+18-59 / 64 \div 60 / 65+
$$

Fig. 7. Polish population in the years $2008-2050$ broken down by age groups budget (million persons)

Source: own calculations based on GUS data.

The growing share of working age population in general would increase the burden on the system (Figure 8) and a drop in efficiency of the pension system (Figure 9). The number of retirees will grow with a strong decline in the number of contribution deposited persons (Figure 10). 


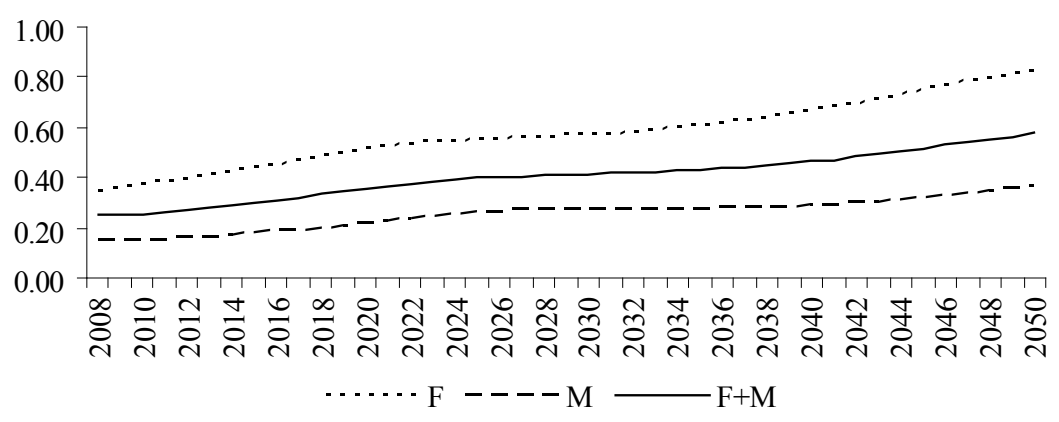

Fig. 8. Load indicator system in the years 2008-2050

Source: own calculations based on GUS data.

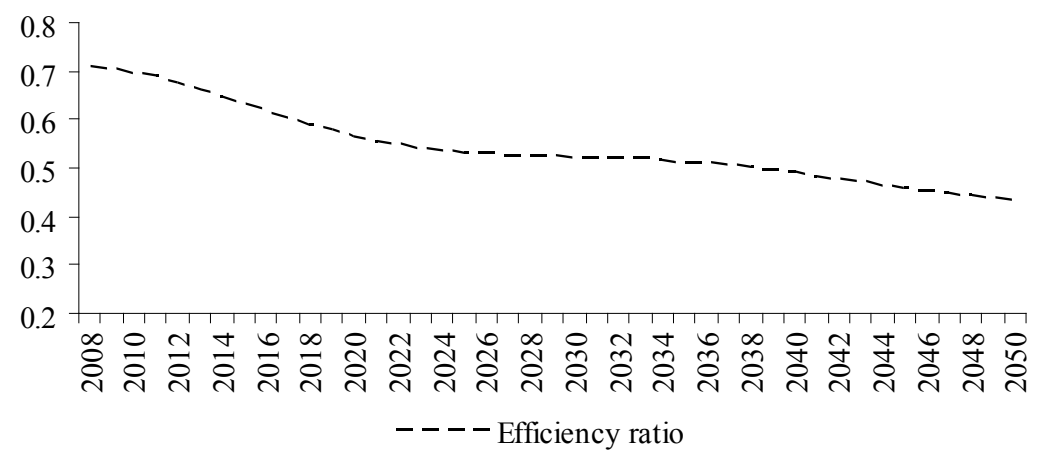

Fig. 9. Efficiency ratio of the pension system in Poland in years 2008-2050

Source: own calculations based on GUS data.

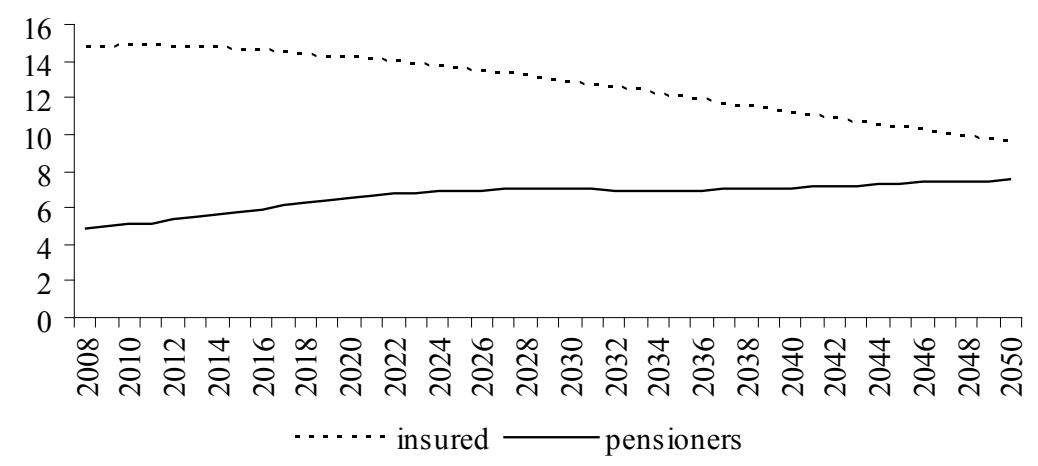

Fig. 10. The number of insured persons and pensioners in the years 2008-2050 Source: own calculations based on GUS data. 
Changes in the pension reform introduced in 1999 are based on an entirely new approach to revenue and expenditure of the Social Insurance Fund. First of all, created the so-called SIF. Pension Fund and identified the sources of revenue and expenses. The connection between the size of future benefits paid in the period of professional activity, and actuarial methods used to determine the average life expectancy of people entering retirement age, and from that conditional amount of monthly benefits. All this meant that the cost of the system under the I pillar in the future will be smaller compared with the expenditure they have to bear the old system. In addition, new system solutions, lead in the long run to its full capacity. This perspective, of course, depends on the scenario. In this scenario, the revenue and expenditure equalization of PF will be about 2,035 years (Figure 11).

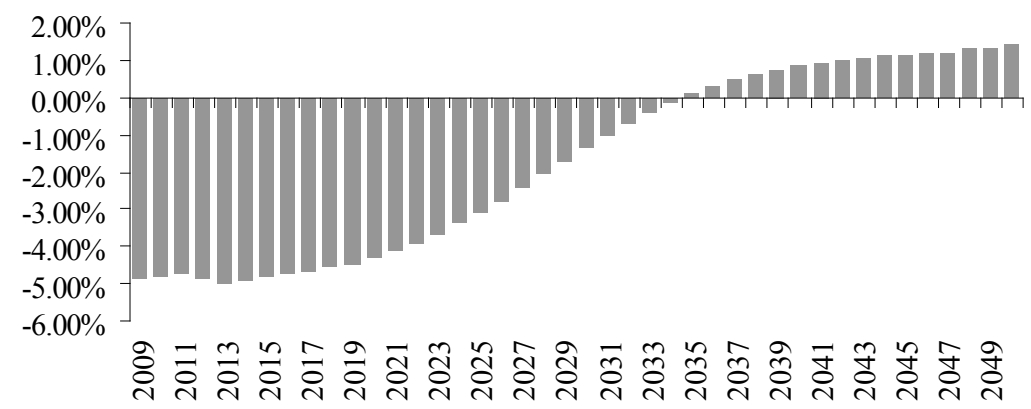

Fig. 11. Annual Balance Pension Fund in the projection period to 2050 as a percentage of the total annual basis of contribution

Source: own calculations based on GUS data.

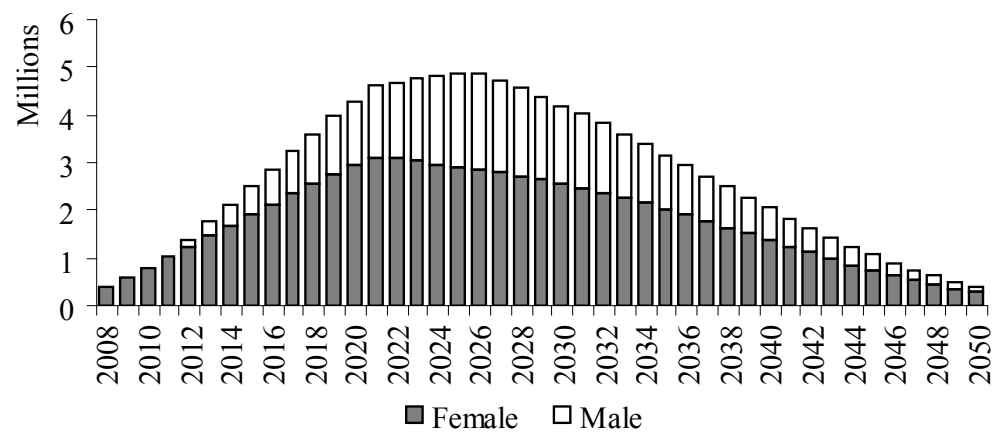

Fig. 12. The share of the number of retirees with high-pressure vintages in the total number of pensioners in the projection period to 2050

Source: own calculations based on GUS data. 
In the scenario, the Pension Fund will not always require financial support, since the year 2035 there is a positive balance in this period means DRF will not have to be used. While in the failure of the system (year 2009-2034) DRF measures should support the process of distribution. Figure 16 shows the need for measures to support FE scenario in the coming years.

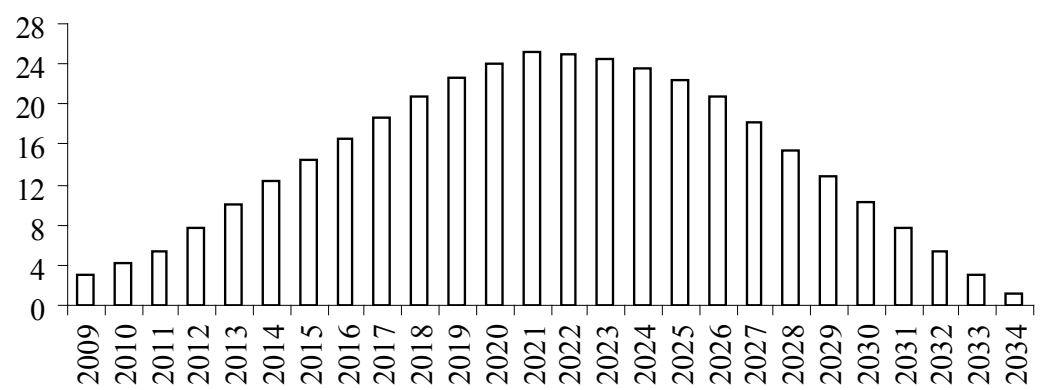

Fig. 13. DRF demand projection for the period to 2050 as a percentage of the total annual basis of contribution

Source: own calculations based on GUS data.

\section{Conclusions}

The study leads to conclusions on the Demographic Reserve Fund, Pension Fund and the entire pension system. First of all, the Demographic Reserve Fund in its current legal status (income limit) is not able to meet the deficit of the Pension Fund in the future. Maintaining the stability of the pension system in the face of an aging population requires changes in the labor market leading to activation of pre-retirement age and retirement. The biggest impact on improving the condition of the Pension Fund and reduce the need Demographic Reserve Fund is to increase the retirement age.

\section{Notes}

1 Pociecha (2003), p. 15.

2 Act of 13 October 1998 the Social Security System (Diary Set 137, pos. 887 as amended).

3 Forecast revenues... (2003).

4 See Kryńska, Suchecka, Suchecki (1998). 


\section{References}

Act of 13 October 1998 the Social Security System (Diary Set 137, pos. 887 as amended).

Binczycka-Majewska, T. (2001). Demographic Reserve Fund to the risks of old age security system, Work and Social Protection 2001/10, Warszawa: PWE.

Economic Forecasting. (2001). M. Cieślak (Ed.). Oxford University Press.

Economic implications of achieving the retirement age for the baby-boom generations. (2003). J. Comfort (Ed.). Kraków: AE.

Ekonomiczne konsekwencje osiagania wieku emerytalnego przez generacje powojennego wyżu demograficznego. (2003). J. Pociecha (Ed.). Kraków: AE.

Forecast revenues and expenditures of the Pension Fund to Fund 2050 (2003). Warsaw: Social Security.

Holzer, J. (2005). Demography, Oxford University Press.

Kryńska, E., Suchecka, J. Suchecki, B. (1998). Forecast supply and demand for labor in Poland until 2010, Warsaw: IPiSS.

Social expenditure in the period 2000-2020 - Report on the model of "social budget" (2003) Ed. I. Woycicki, Warsaw: IBnGR.

The financial statements of the Demographic Reserve Fund for the year ended December 31, 2003 (2004), Warsaw: Social Security.

Zeliaś, A. (1997). Theory of forecasts, Warsaw: PWE. 